\title{
Assessment of vasectomy awareness in different communities of Gujurat
}

\author{
Karnik Patel, Dharmik Patel and Kaushalendra Tripathi* \\ Department of Medicine, V.S. Hospital, Smt.N.H.L. Municipal Medical College, Ahmedabad, India
}

\begin{abstract}
Vasectomy is an important surgical method of birth control, which is of significance in overpopulated countries, such as India and china, its importance is dictated by a significant number of factors including its superstitious perceptions which deter the men from undergoing such a procedure, leading to woman who sometimes, are forced to undergo contraceptive procedures for the same reasons, we are discussing here, the causes and how to further improve its accessibility and spread knowledge about vasectomy, to prevent overpopulation and further propagate family planning.
\end{abstract}

\section{Introduction}

A vasectomy is considered a permanent method of birth control. A vasectomy prevents the release of sperm when a man ejaculate. It is a very effective contraceptive method only 1 to 2 women out of 1,000 will have an unplanned pregnancy in the first year after their partners have had a vasectomy [1].

There are several types of vasectomies and the procedures to go about these may vary. These procedures are incision and no-incision (or "no-scalpel") methods.

Vasectomies are usually done to men who make a decision to no longer continue his biological family, believe or are told that other methods of contraception are unacceptable, do not want to pass down a hereditary illness or disability has a partner whose health would be threatened by a future pregnancy, has concerns along with his partner about the side effects of other methods of contraception, agrees with his partner agree that their family is complete, and no more children are wanted,wants to spare his partner the surgery and expense of tubal sterilization (sterilization for women is more complicated and more costly)

In India, men are often paid to get a vasectomy under the terms of different government schemes usually for reasons such as population control $[2,3]$. However, despite the certainty, safety and even cost benefit of vasectomy, Indian men seldom undergo the procedure. This is mostly due to social stigma, fear of the unknown, and possibly because many people are averse to any medical procedures (since the alteration of a part of the body is a significant decision). Along with these reasons, the concept of contraception itself is commonly taken lightly in many developing countries. Even after various campaigns to promote methods of contraception for reasons such as population control, its awareness is not given much importance; and for some areas under the poverty line, it is usually absent.

The social stigma surrounding vasectomy has a considerable influence on the opinions of Indian men and sometimes also their wives on considering undergoing the procedure. In a society where patriarchal traditions prevail, succumbing to the ideas of undergoing what some may see as "castration" seems masculine and looked down upon by others.

For many, lack of education of the subject often leads to a fear of unknown consequences of the procedure. For example, some may believe that it results in fluctuating hormonal changes or even permanent changes to the physical appearance of a man. Certain uneducated persons may also have a negative perception that the removal of a reproductive organ which makes them barren will label them as no longer an 'ideal' female or male.

With these varying opinions about the idea of male sterilizationparticularly the procedure of vasectomy a study was conducted on males aged between twenty to forty-five years having at least one child, from different areas in Ahmedabad, Gujarat, India about the awareness of vasectomy and to assess their attitudes towards vasectomy.

\section{Review of literature}

Vasectomy is a surgical procedure for permanent contraception in males. The procedure is regarded as permanent because its reversal is costly and often does not restore the male sperm count or sperm motility to pre-vasectomy levels.

During the procedure, the male vas deferens is severed and then tied or sealed in a manner to prevent the sperm from entering into the seminal stream that is ejaculation and thereby prevent fertilization. Men with vasectomies have a very small chance (nearly zero) of successfully impregnating a woman but a vasectomy has no effect on rates of sexually transmitted infections (STIs) for married and monogamous men.

${ }^{*}$ Correspondence to: Kaushalendra Tripathi, Department of Medicine, V.S. Hospital, Smt.N.H.L. Municipal Medical College, Ahmedabad, India, Tel: (079) 26578452; E-mail: kausha7849@gmail.com

Key words: vasectomy, sexual reproduction, awareness, family planning

Received: November 12, 2018; Accepted: November 30, 2018; Published: December 03, 2018 
After vasectomy, the testes remain in the scrotum where Leydig cells continue to produce testosterone and other main hormones that continue to be secreted in the bloodstream. Thus, vasectomy has no effect on the masculinity of a person. After a short recovery at the hospital, the patient is sent home to rest. Since the procedure is minimally invasive the vasectomy patients can resume their sexual behavior within a week with little or no discomfort.

When the vasectomy is complete with recovery, sperms cannot exit the body through the penis. Sperms are still produced by the testicles however they are soon broken down and absorbed by the body. Membranes in the epididymis absorb much of the fluid content and much solid content is broken down by the responding macrophages and then reabsorbed via the bloodstream.

Hospitalization is not normally required as the procedure is not complicated, incisions are small however some may find it necessary for varying reasons. It's a very effective method for contraception though it does not exclude the chances of STDs. It is in fact of lower cost and less invasive than tubal ligation.

However, current possible short-term complications include infection, bruising and bleeding into the scrotum resulting in the collection of blood known as hematoma. The primary long-term (yet rare) complications of vasectomy are chronic pain conditions or syndromes that can affect any of the scrotum, pelvis or lower abdominal regions collectively known as Post-Vasectomy Pain Syndrome.

Because the procedure is considered a permanent method of contraception and is not easily reversed, men are usually counseled/ advised to consider how the long-term outcome of vasectomy might affect them both emotionally and physically. The procedure is not often encouraged for young, single men as their chances for biological parenthood are thereby more or less permanently reduced to almost zero.

Government schemes in India have made vasectomy manageable for men and have brought many benefits to the patient as well as compensation for any deaths or failures of the procedure. The government criteria for male sterilization is having two children and being married. However, after one child, one is still eligible for the process. Under present rules, all the beneficiaries of vasectomy operation are given Rs. 1100/- cash as motivation.

In India, the vasectomy and vasectomy (sterilization) program is non-compulsory and the couples choose a method best suited to them. In the year 2013 to 2014, 4092806 sterilization operations have been performed in the country [2]. In case of death or failure of sterilization, the government provides compensation as per details given below.

Under section I-IA, Rs.2,00,000 for: "Death following sterilization (inclusive of death during process of sterilization operation) in hospital or within 7 days from the date of discharge from the hospital" 2

Under Section I-IB, Rs.50,000 for: "Death following sterilization within 8 to 30 days from the date of discharge from the hospital" 2

Under Section I-IC, Rs.50,000 for: "Failure of Sterilization" 2 Under I-ID, actual not exceeding Rs 25,000"Cost of treatment in hospital and up to 60 days arising out of Complication following Sterilization operation (inclusive of complication during process of sterilization operation) from the date of discharge" 2 Under II, Up to Rs. 2,00,000/-"Indemnity Insurance per Doctor/facility but not more than 4 cases in a year" [2].

\section{Methods and materials}

\section{Design of study-cross sectional study}

- Subjects: 117 married men with at least one child between the age group 20 to 45 years

\section{Inclusion criteria}

- Male between 20-45 years of age

- Married with at least one child

\section{Exclusion criteria}

- Already undergone vasectomy

- People unwilling to fill the questionnaire

- Wife has undergone a method of permanent contraception

\section{Ethical considerations}

- Verbal consent was taken.

- Those who have showed interest to get vasectomy were referred to government hospital.

\section{Implementation of program/methodology}

A questionnaire was prepared keeping in mind various characters necessary for assessment of knowledge and attitude of Married men between $20-45$ years of age.

The questionnaire was used to collect data from door to door community visit after taking the oral consent of the respective individual.

The data obtained through the questionnaire was entered in an Excel spreadsheet. The EPI info software was used to analyze the data and find statistical correlation and significance using the Chi Square Test

\section{Evaluation}

- To find out proportion of percentages and mean scores of various questions to be answered in the questionnaire

- To compare using bar graph

- Analyze data using chi square test

\section{Limitation}

- We did not verify, or cross-checked information provided by subjects

- Limited sample size

\section{Resources}

1. Questionnaire: 130

2. Cost: Rs 260

\section{Results and discussion}

Out of the total men, majority of them being Hindus, fell in age group of 27 to 32 years and had received primary education. Most of the men had 2 children with their primary method of contraception being a condom.

Assessing their knowledge, it was found that $47 \%$ of the men believed that vasectomy will make them lose their sexual abilities. Majority of 


$\begin{array}{ccc}\text { Average } & \text { Median } & \text { Range } \\ 5.2 / 11 \text { points } & 5 / 11 \text { points } & 0-10 \text { points }\end{array}$

Total points distribution

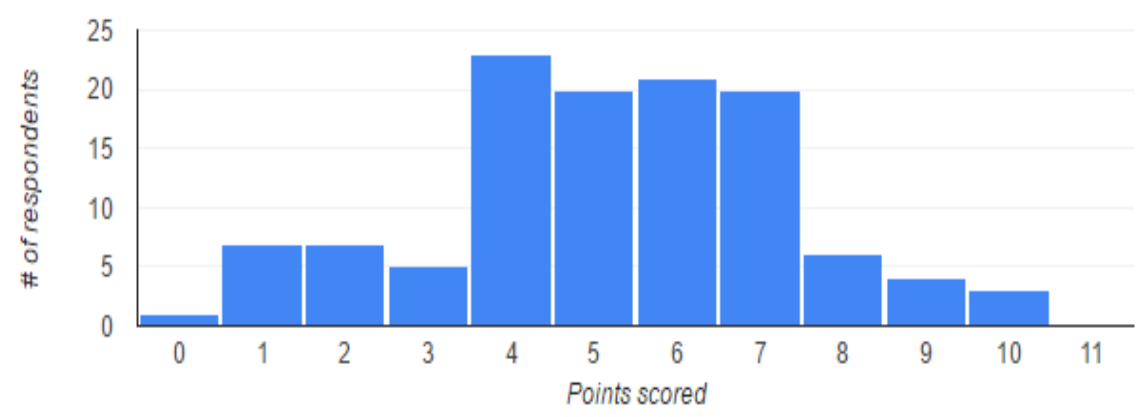

Figure 1. Observations

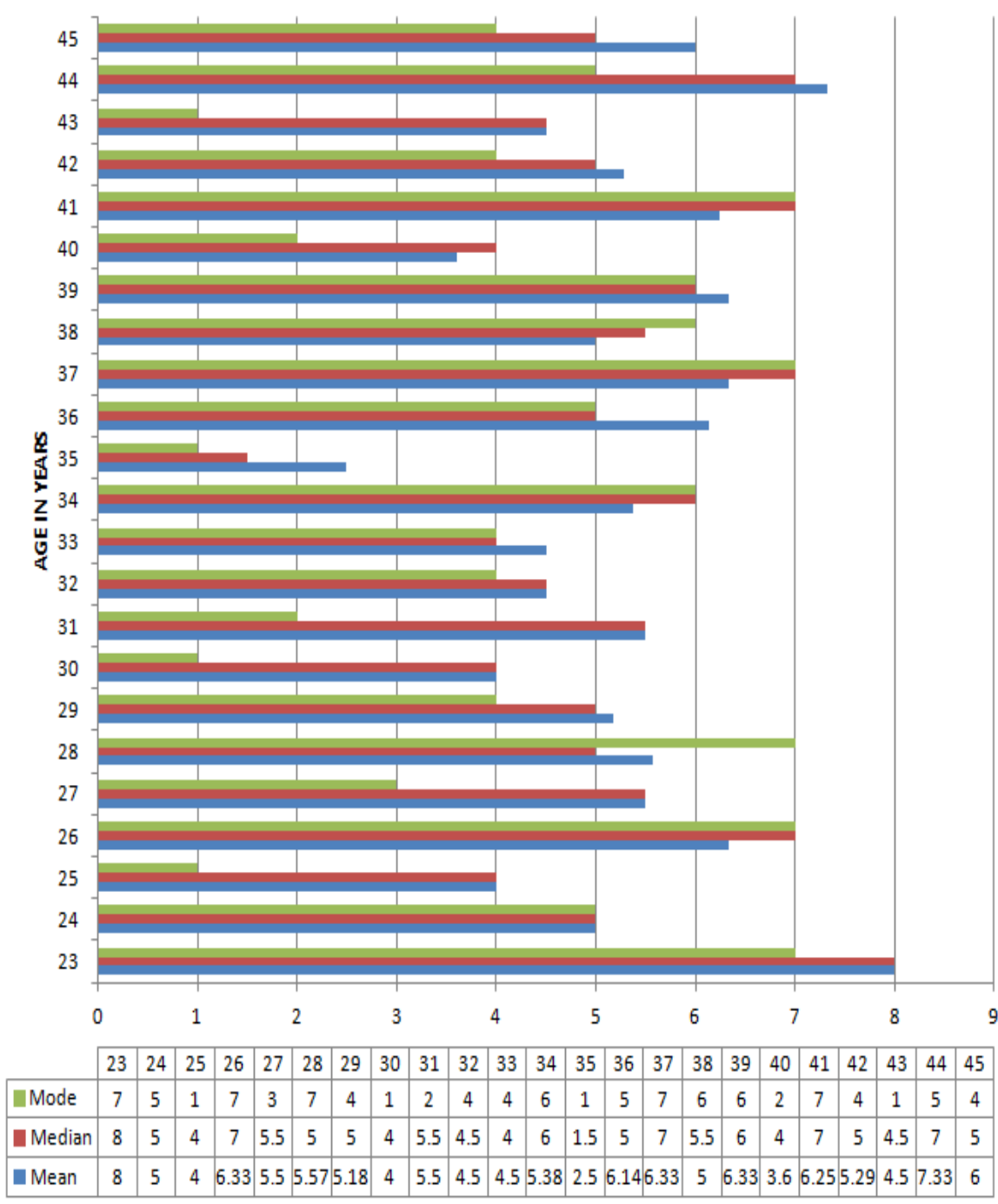

Figure 2. Age vise score distribution. There was no relation between knowledge and age 


\section{Age Distribution in Sample}

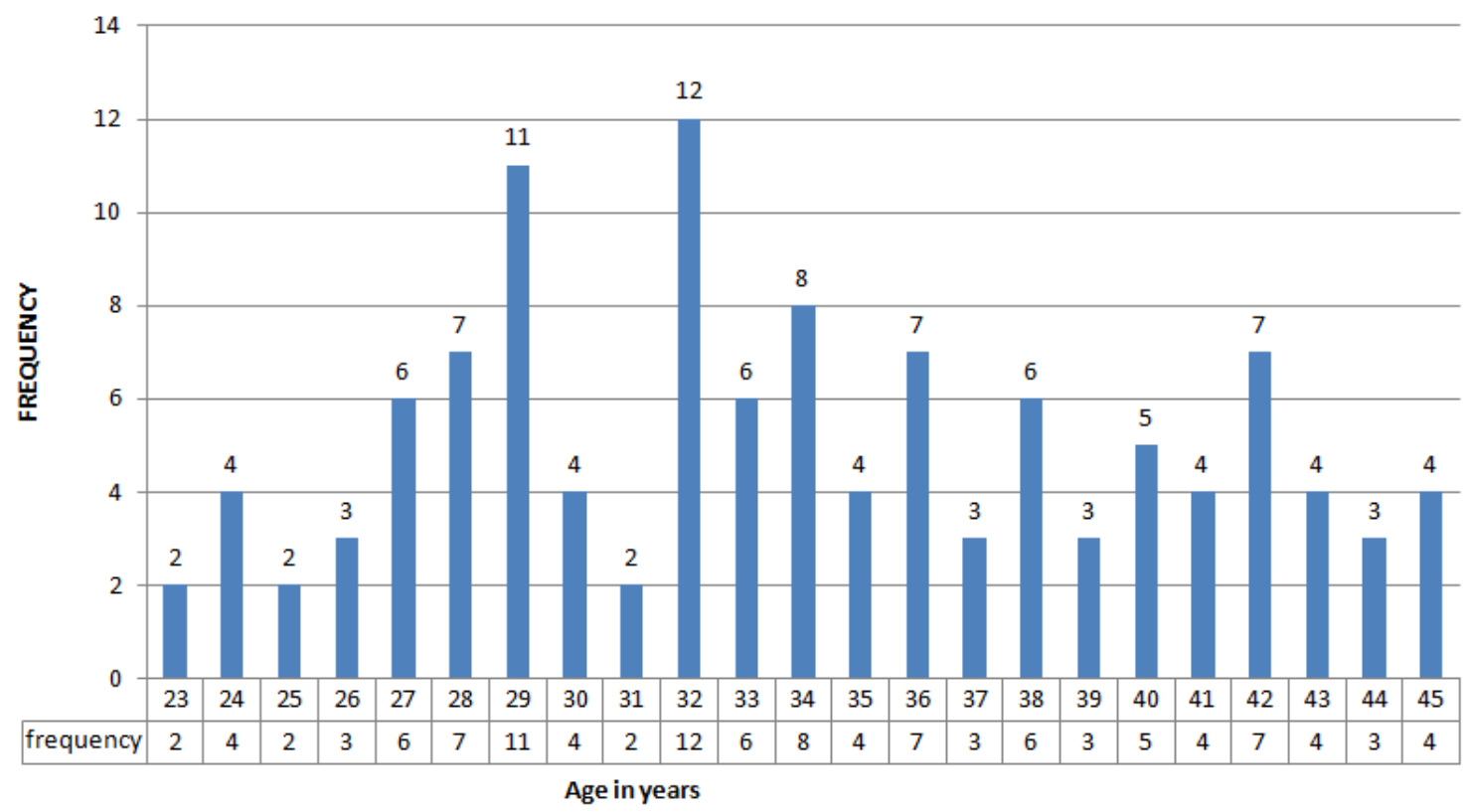

Figure 3. Age distribution. MEAN: 33.9573; Variance: 5.4723; Standard Deviation: 5.9559; Median: 33; Mode: 32

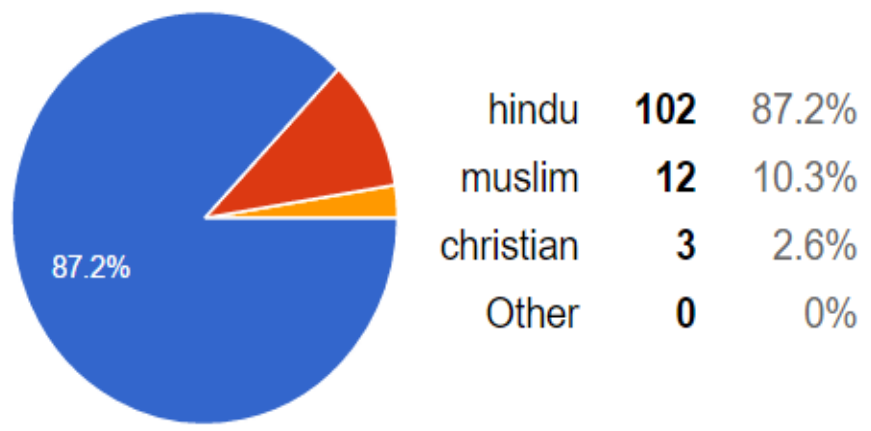

Figure 4. Religion. Interpretation: The population of other than Hindus is less than $15 \%$

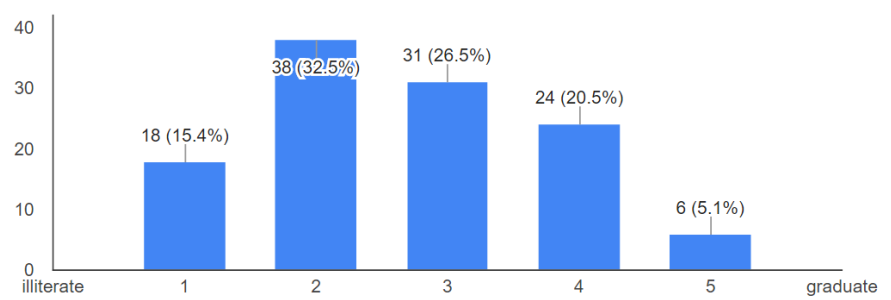

Figure 5. Education. Interpretation: From Sample size of 117 men, 69 men (59\%) had studied till 10th grade

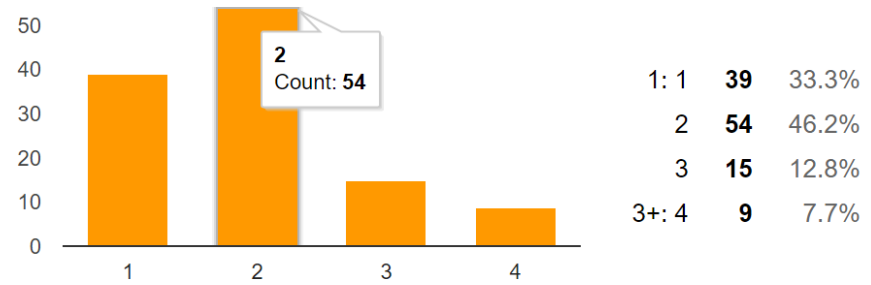

Figure 6. Number of children. Interpretation: $66 \%$ men are eligible for taking advantages of vasectomy related government schemes. Interpretation: From Sample size of 117 men, 73 men $(62 \%)$ have been married since 5 to 15 years 


\section{Interpretation:}

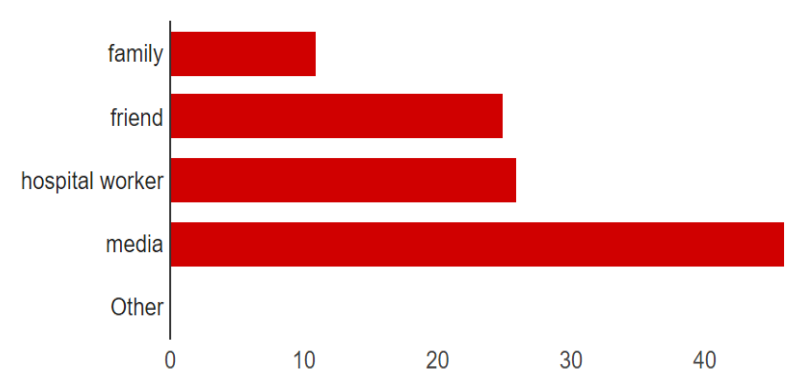

- From Sample size of 117 men, 79 men $(72 \%)$ have heard term vasectomy due to governmental vasectomy awareness activities

family $\mathbf{1 1} \quad 12.1 \%$

friend $25 \quad 27.5 \%$

hospital worker $\quad 26 \quad 28.6 \%$

media $\quad \mathbf{4 6} \quad 50.5 \%$

Other $\quad \mathbf{0} \quad 0 \%$

2. I believe that a vasectomy will it change a man's physical appearance.

$83 / 117$ correct responses

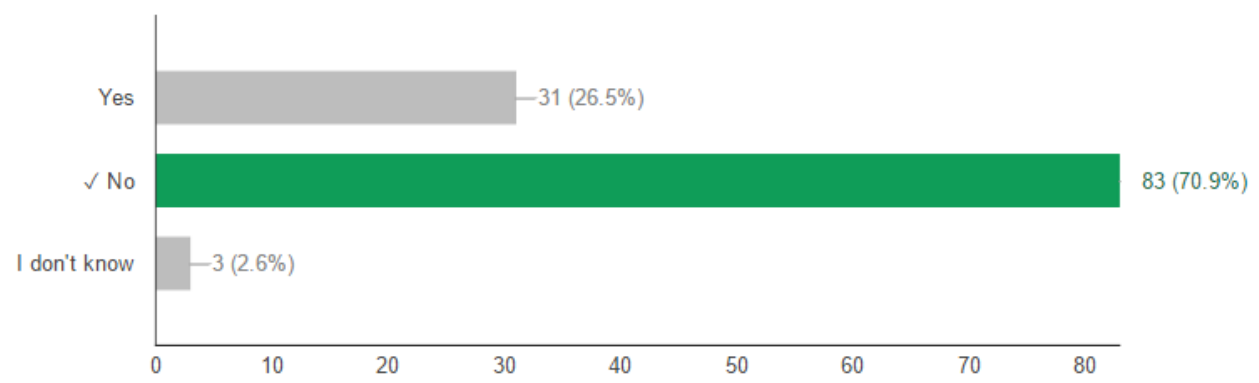

3. It will cause long lasting pain afterwards.

$67 / 117$ correct responses

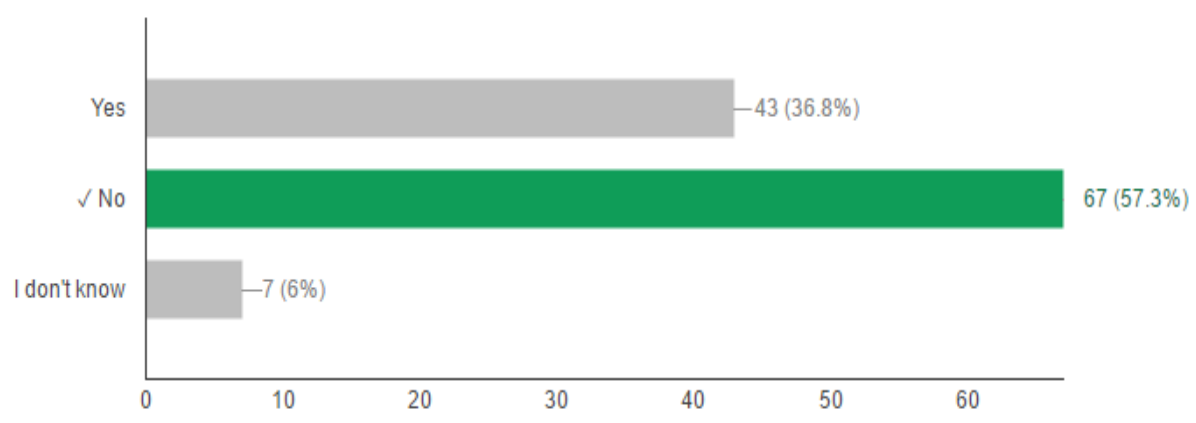


4. A man needs to use another contraceptive after vasectomy after long duration to prevent pregnancy.

$68 / 117$ correct responses

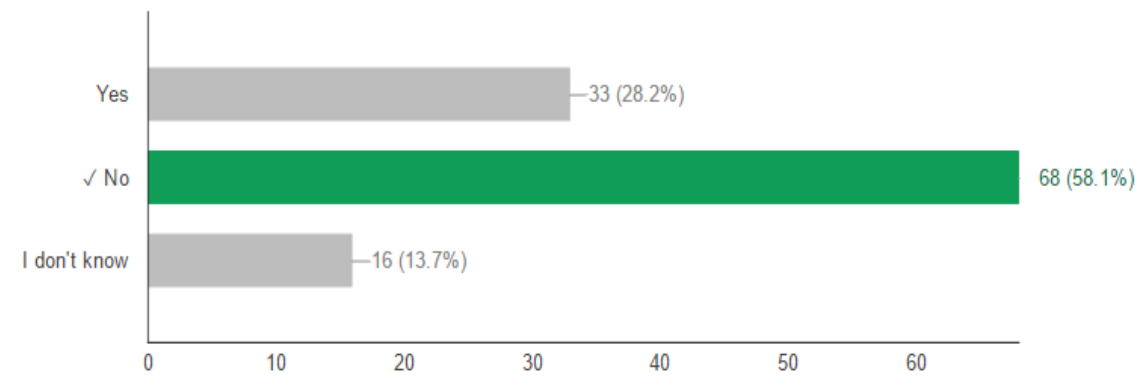

5. Is there a medical method to check if the vasectomy is working?

$55 / 117$ correct responses

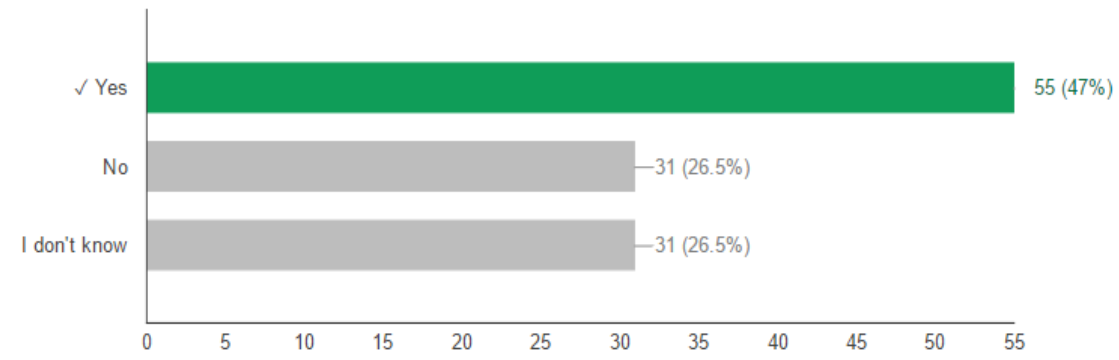

6. After vasectomy, I believe that I have to wait a certain period of time before it is effective?

$59 / 117$ correct responses

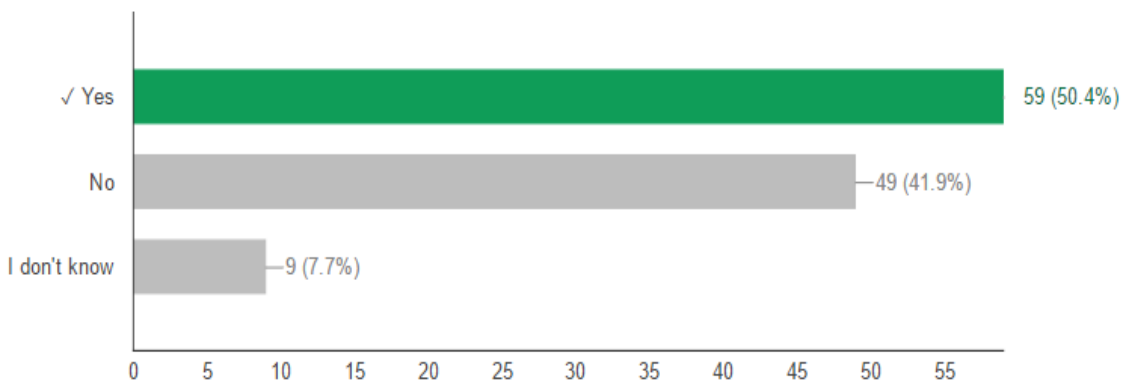


7. It increases the chance of STDs in man having extramarital affairs.

$49 / 117$ correct responses

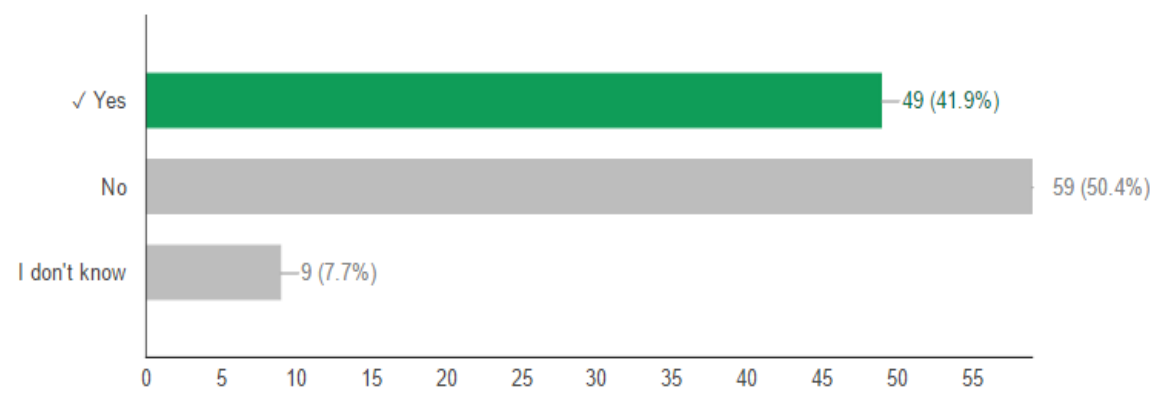

8. Do you know the nearest care centre that provides free vasectomies?

$41 / 117$ correct responses

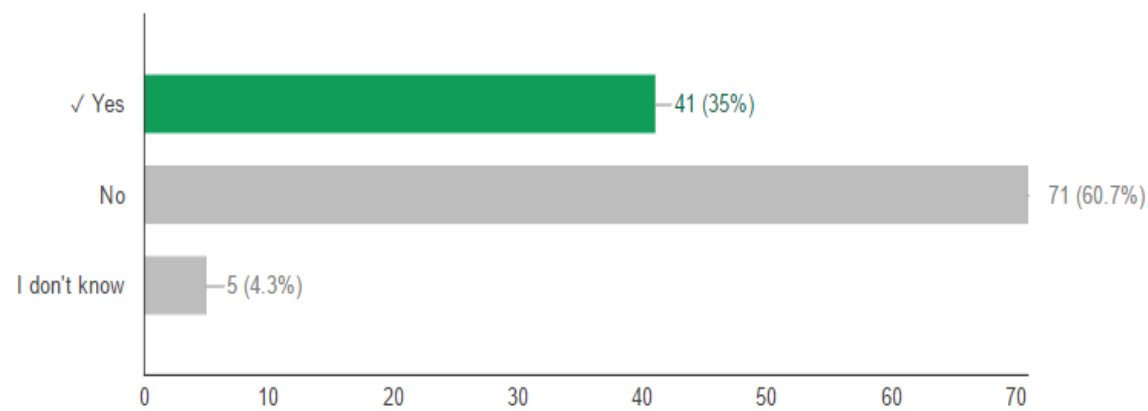

9. Do you know about any government schemes (for example Revise Compensation Scheme) for vasectomies?

$53 / 117$ correct responses

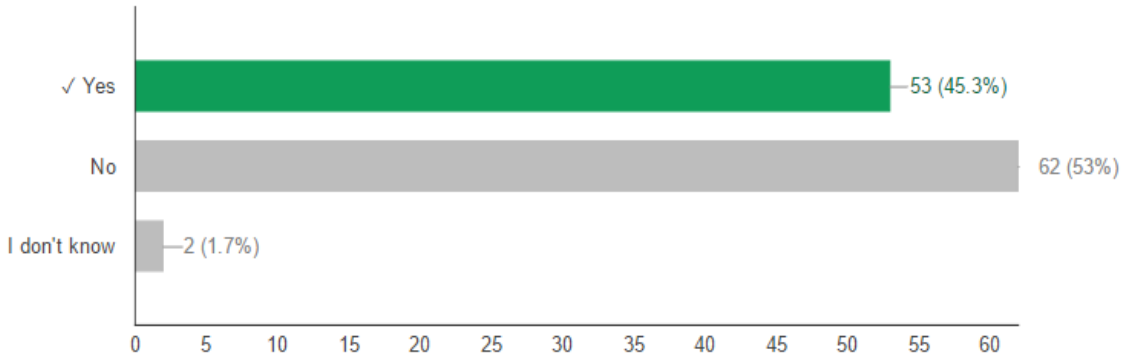




\section{Do you know about insurance for vasectomies?}

$39 / 117$ correct responses

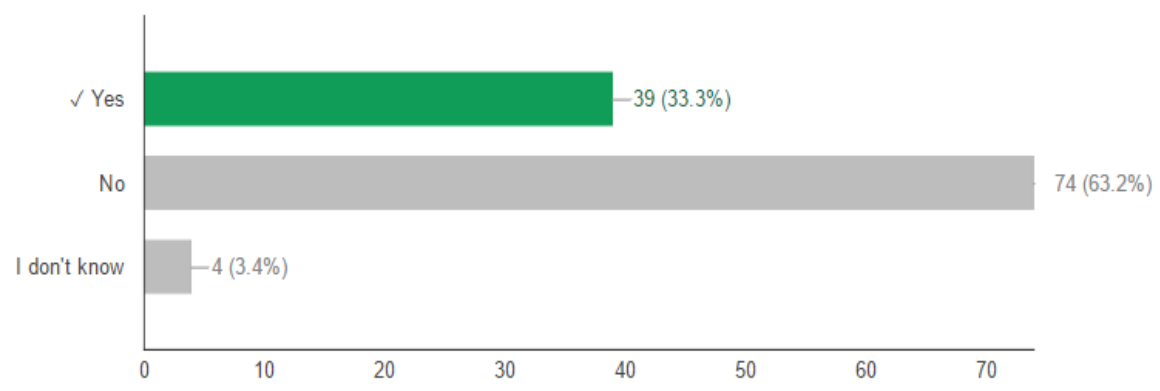

11. Is vasectomy reversible?

$34 / 117$ correct responses

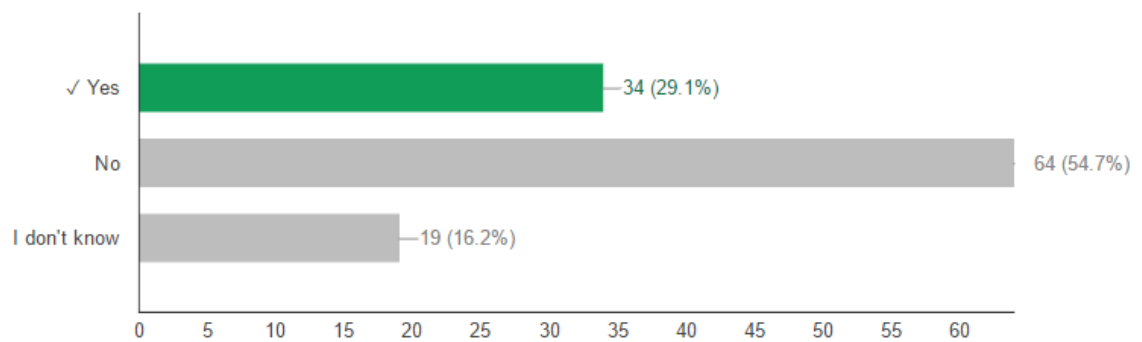

Questions that whose answer was most

5. Is there a medical method to check if the vasectomy is working?

7. It increases the chance of STDs in man having extramarital affairs.

8. Do you know the nearest care centre that provides free vasectomies?

9. Do you know about any government schemes (for example Revise Compensation Scheme) for vasectomies? 53 / 117

10. Do you know about insurance for vasectomies?

11. Is vasectomy reversible?

How long since you've been married? (117 responses)

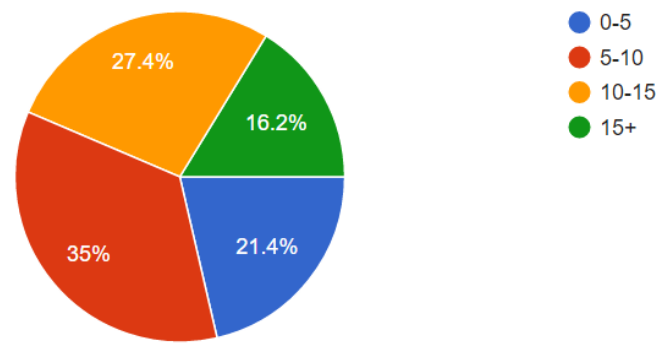

Figure 7. Questionnaire statistics 


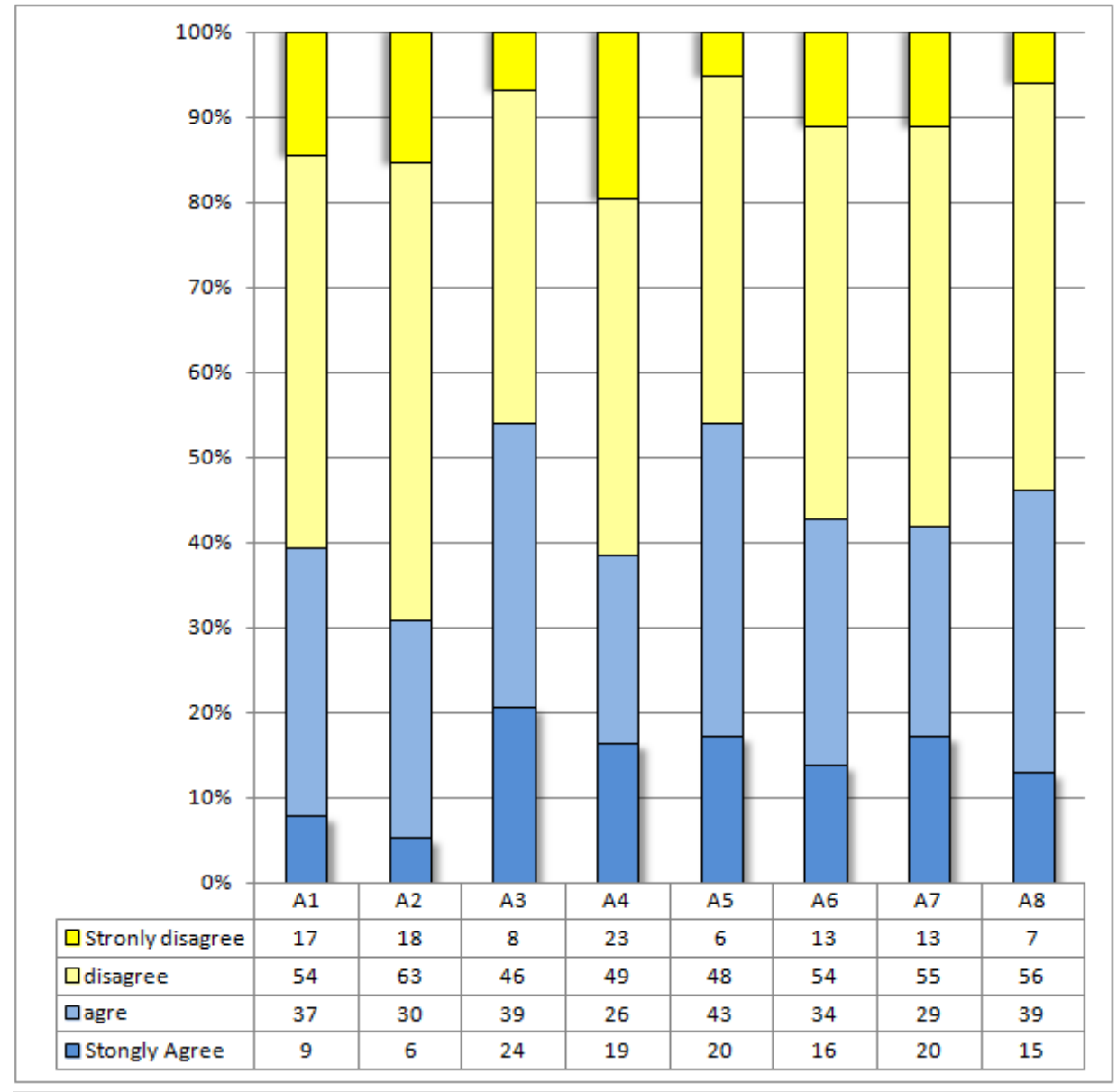

\section{ATTITUDE}

\section{I have considered getting a vasectomy.}
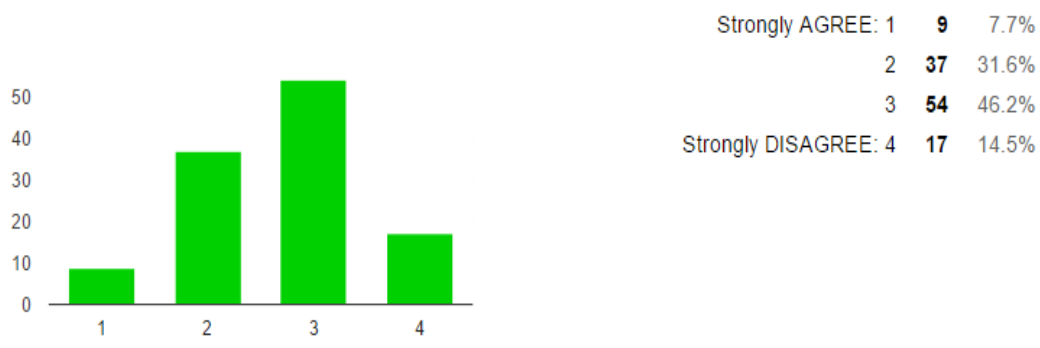

Strongly DISAGREE: $4 \quad 17 \quad 14.5 \%$

\section{Vasectomy is castration and should not be done?}

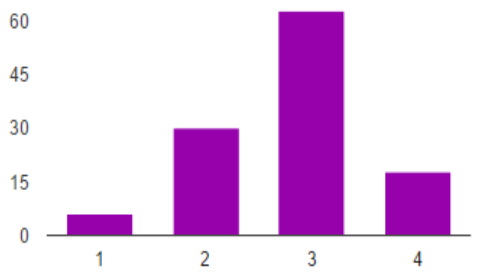
Strongly AGREE: $1 \quad 6 \quad 5.1 \%$
$2 \quad 30 \quad 25.6 \%$
$3 \quad 63 \quad 53.8 \%$

Strongly DISAGREE: $4 \quad 18 \quad 15.4 \%$ 
3. Vasectomy makes men more promiscuous?

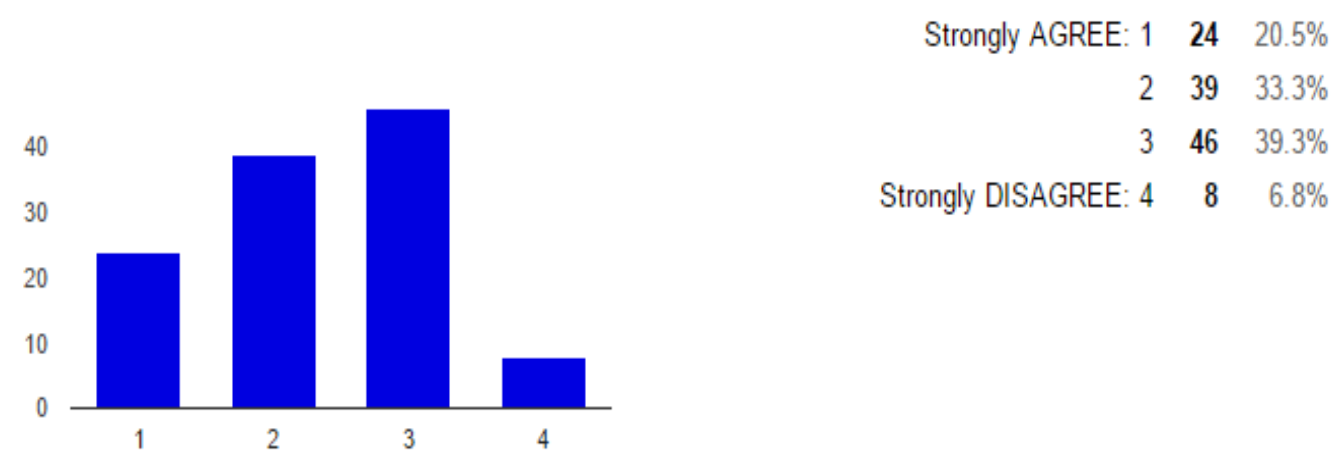

4. It's against my culture/religious beliefs for a man to get a vasectomy?

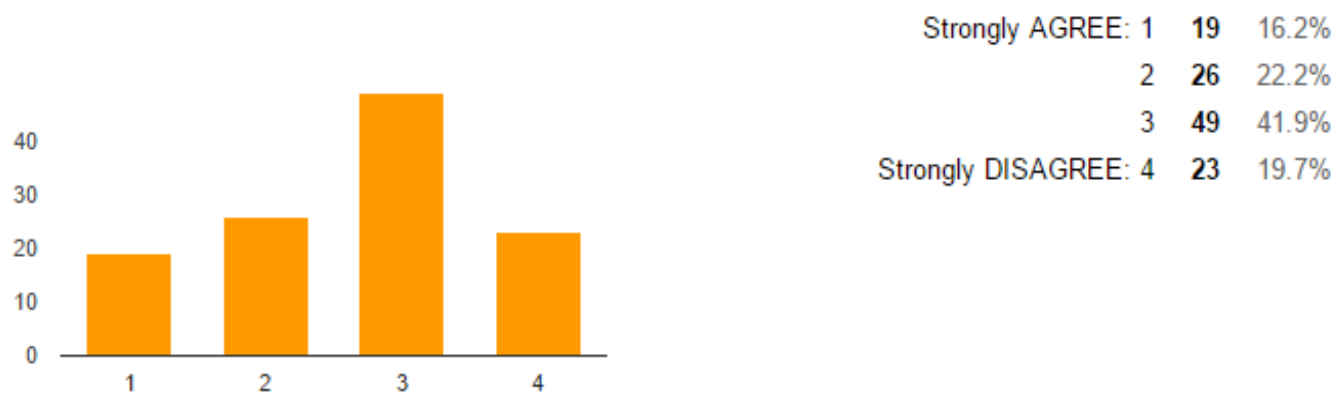

5. Men should be primarily responsible for decision making on family planning methods to utilize.

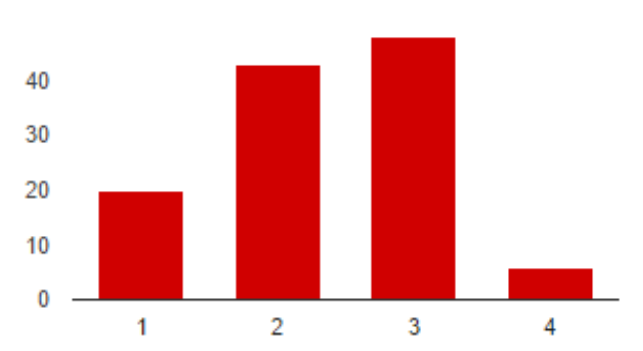

$\begin{array}{rrr}\text { Strongly AGREE: } 1 & \mathbf{2 0} & 17.1 \% \\ 2 & \mathbf{4 3} & 36.8 \% \\ 3 & \mathbf{4 8} & 41 \% \\ \text { Strongly DISAGREE: } 4 & 6 & 5.1 \%\end{array}$

6. It's preferable that permanent sterilization should only be for females?

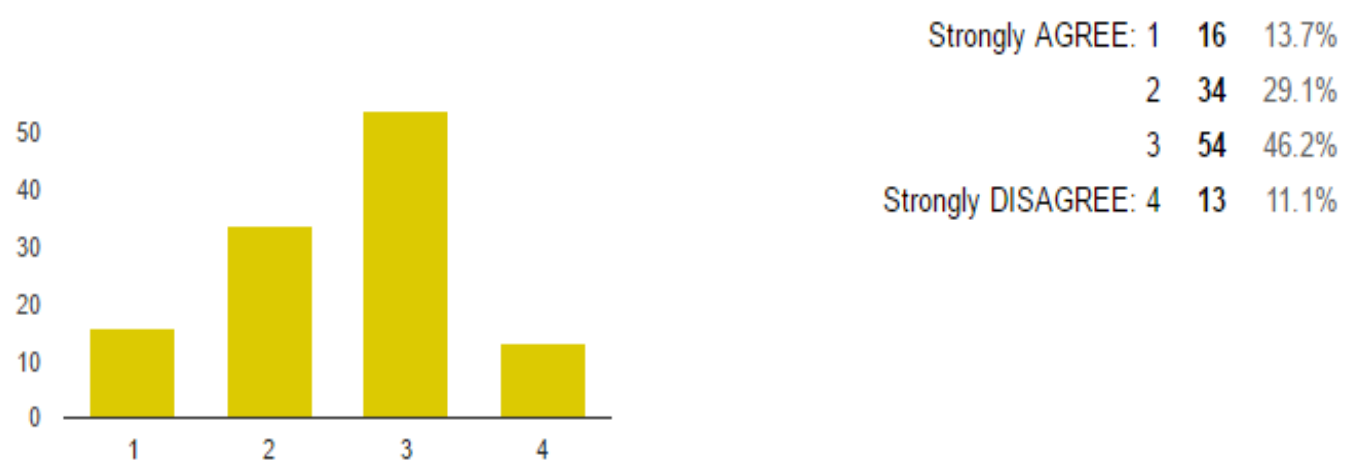


7. The recovery time it takes after the surgery effects my decision on getting a vasectomy (Due to hindrance from work, etc.)

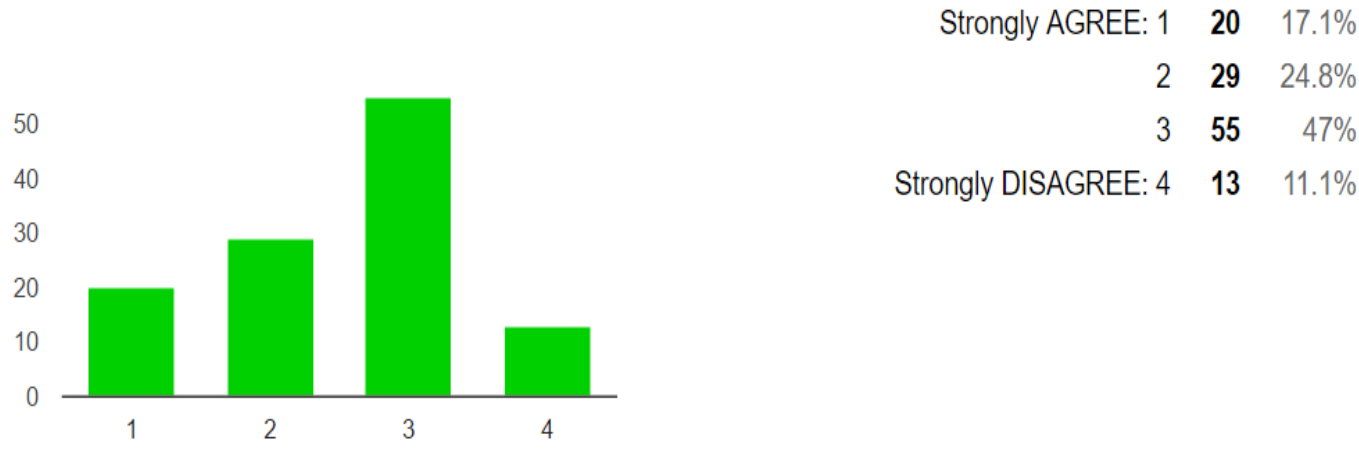

8. I fear my acceptance in society if I got/have gotten a vasectomy.

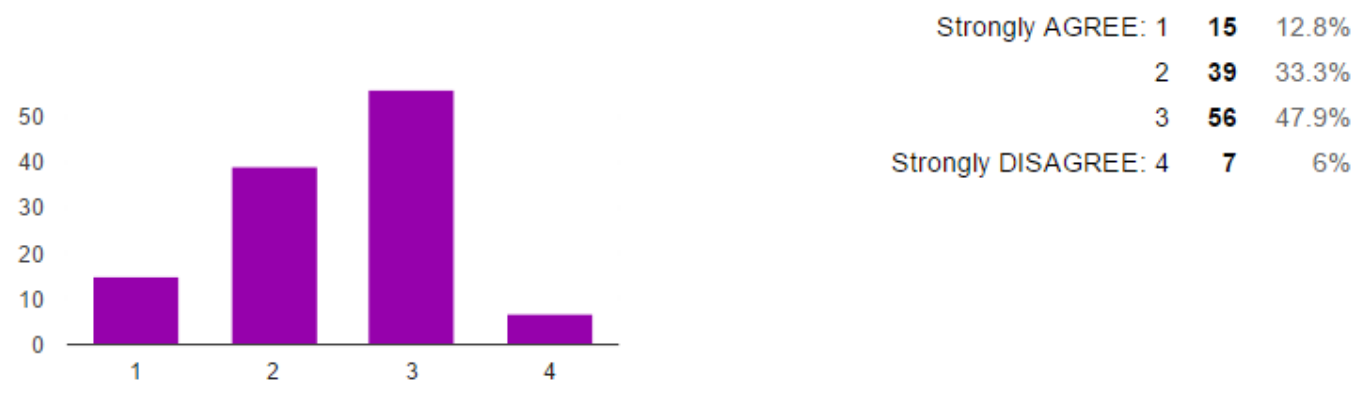

Association between attitude of men should be decision maker (A5) and their belief that permanent contraceptive method are for women only (A6). P Value: 0.0001.

\begin{tabular}{|c|c|c|c|c|c|}
\hline \multicolumn{6}{|c|}{ A6 } \\
\hline A5 & 1 & 2 & 3 & 4 & TOTAL \\
\hline 1 & 3 & 13 & 4 & 0 & 20 \\
\hline Row \% & 15.0 & 65.0 & 20.0 & 0.0 & 100.0 \\
\hline Col\% & 18.8 & 38.2 & 7.4 & 0.0 & 17.1 \\
\hline 2 & 8 & 16 & 17 & 2 & 43 \\
\hline Row \% & 18.6 & 37.2 & 39.5 & 4.7 & 100.0 \\
\hline Col\% & 50.0 & 47.1 & 31.5 & 15.4 & 36.8 \\
\hline 3 & 5 & 3 & 33 & 7 & 48 \\
\hline Row\% & 10.4 & 6.3 & 68.8 & 14.6 & 100.0 \\
\hline Col\% & 31.3 & 8.8 & 61.1 & 53.8 & 41.0 \\
\hline 4 & 0 & 2 & 0 & 4 & 6 \\
\hline Row \% & 0.0 & 33.3 & 0.0 & 66.7 & 100.0 \\
\hline Col\% & 0.0 & 5.9 & 0.0 & 30.8 & 5.1 \\
\hline TOTAL & 16 & 34 & 54 & 13 & 117 \\
\hline Row \% & 13.7 & 29.1 & 46.2 & 11.1 & 100.0 \\
\hline Col\% & 100.0 & 100.0 & 100.0 & 100.0 & 100.0 \\
\hline
\end{tabular}

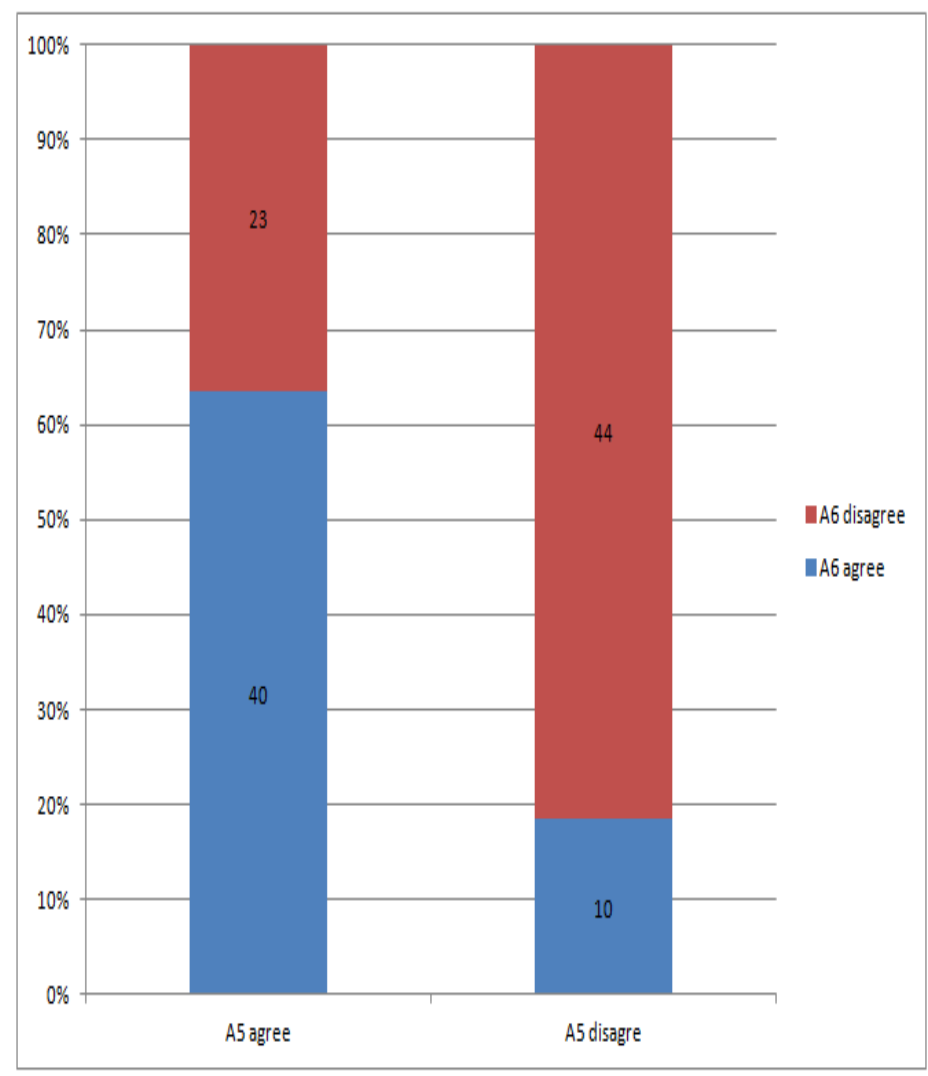




\begin{tabular}{|l|r|r|r}
\hline A6/A5 & A5 agree & A5 disagree & total \\
\hline A6 agree & 40 & 10 & 50 \\
\hline A6 disagree & 23 & 44 & 67 \\
\hline total & 63 & 54 & 117 \\
\hline
\end{tabular}

P - Value: 0.0001

$\chi 2=52.96$

Degree of freedom: 9

Interpretation:

Majority of the males who believed that the responsibility of decision regarding the methods of family planning solely rests on them also believed that the permanent sterilization should only be for females. Association between education and myth (p:0.0043).

\section{I believe that a vasectomy will make a man lose his sexual abilities.}

\begin{tabular}{llll}
\hline \hline Education & No & Yes & TOTAL \\
\hline Illiterate & 3 & 15 & 18 \\
Row\% & 16.7 & 83.3 & 100.0 \\
Col\% & 5.0 & 27.3 & 15.4 \\
\hline Primary & 22 & 16 & 38 \\
Row\% & 57.9 & 42.1 & 100.0 \\
Col\% & 36.7 & 29.1 & 32.5 \\
Secondary & 18 & 13 & 31 \\
Row\% & 58.1 & 41.9 & 100.0 \\
Col\% & 30.0 & 23.6 & 26.5 \\
\hline Higher Secondary & 16 & 8 & 24 \\
Row\% & 66.7 & 33.3 & 100.0 \\
Col\% & 25.0 & 14.5 & 20.5 \\
Graduate & 3 & 3 & 6 \\
Row\% & 50.0 & 50.0 & 100.0 \\
Col\% & 3.3 & 5.5 & 5.1 \\
\hline TOTAL & 62 & 55 & 117 \\
Row\% & 53.0 & 47.0 & 100.0 \\
Col\% & 100.0 & 100.0 & 100.0 \\
\hline
\end{tabular}

Interpretation

Education is strongly associated with myth that a vasectomy will make a man impotent.

As literacy increases proportion of men those who believe in this myth decreases.

This association is statistically very significant because $\mathrm{p} \leq 0.05$

Association between knowledge of chances getting STDs in polygamous men and attitude towards post vasectomy promiscuousness (P-Value:0.0001). 


\begin{tabular}{|c|c|c|c|c|c|}
\hline \multicolumn{6}{|c|}{ Vasectomy makes men more promiscuous } \\
\hline $\begin{array}{l}\text { It increases the chance } \\
\text { of STDs in men having } \\
\text { extramarital affairs. }\end{array}$ & Strongly Agree & Agree & Disagree & Strongly Disagree & TOTAL \\
\hline $\begin{array}{l}\text { I don't know } \\
\text { Row \% } \\
\text { Col \% }\end{array}$ & $\begin{array}{c}1 \\
11.1 \\
4.2\end{array}$ & $\begin{array}{c}3 \\
33.3 \\
7.7\end{array}$ & $\begin{array}{c}3 \\
33.3 \\
6.5\end{array}$ & $\begin{array}{c}2 \\
22.2 \\
25.0\end{array}$ & $\begin{array}{c}9 \\
100.0 \\
7.7\end{array}$ \\
\hline $\begin{array}{l}\text { No } \\
\text { Row \% } \\
\text { Col \% }\end{array}$ & $\begin{array}{c}3 \\
5.1 \\
12.5\end{array}$ & $\begin{array}{c}19 \\
32.2 \\
48.7\end{array}$ & $\begin{array}{c}32 \\
54.2 \\
69.6\end{array}$ & $\begin{array}{c}5 \\
8.5 \\
62.5\end{array}$ & $\begin{array}{c}59 \\
100.0 \\
50.4\end{array}$ \\
\hline $\begin{array}{l}\text { Yes } \\
\text { Row \% } \\
\text { Col \% }\end{array}$ & $\begin{array}{c}20 \\
40.8 \\
83.3\end{array}$ & $\begin{array}{c}17 \\
34.7 \\
43.6\end{array}$ & $\begin{array}{c}11 \\
22.4 \\
23.9\end{array}$ & $\begin{array}{c}1 \\
2.0 \\
12.5\end{array}$ & $\begin{array}{c}49 \\
100.0 \\
41.9\end{array}$ \\
\hline $\begin{array}{l}\text { TOTAL } \\
\text { Row \% } \\
\text { Col } \%\end{array}$ & $\begin{array}{c}24 \\
20.5 \\
100.0\end{array}$ & $\begin{array}{c}39 \\
33.3 \\
100.0\end{array}$ & $\begin{array}{c}46 \\
39.3 \\
100.0\end{array}$ & $\begin{array}{c}8 \\
6.8 \\
100.0\end{array}$ & $\begin{array}{c}117 \\
100.0 \\
100.0\end{array}$ \\
\hline
\end{tabular}

Interpretation: Males who believed that vasectomy increases the chances of STDs among the ones having extramarital affair also believed that vasectomy makes the men more promiscuous. Association between knowledge of vasectomy related pain and their decision of getting vasectomy based on recovery time (P-Value:0.0036).

\begin{tabular}{|c|c|c|c|c|c|}
\hline \multirow[b]{2}{*}{$\begin{array}{l}\text { It will cause long lasting } \\
\text { pain afterwards. }\end{array}$} & \multicolumn{5}{|c|}{ The recovery time it takes after the surgery affects my decision on getting a vasectomy } \\
\hline & Strongly Agree & Agree & Disagree & Strongly Disagree & TOTAL \\
\hline $\begin{array}{l}\text { I don't know } \\
\text { Row \% } \\
\text { Col \% }\end{array}$ & $\begin{array}{c}0 \\
0.0 \\
0.0\end{array}$ & $\begin{array}{c}3 \\
42.9 \\
10.3\end{array}$ & $\begin{array}{c}2 \\
28.6 \\
3.6\end{array}$ & $\begin{array}{c}2 \\
28.6 \\
15.4\end{array}$ & $\begin{array}{c}7 \\
100.0 \\
6.0\end{array}$ \\
\hline $\begin{array}{l}\text { No } \\
\text { Row \% } \\
\text { Col \% } \\
\end{array}$ & $\begin{array}{c}14 \\
20.9 \\
70.0\end{array}$ & $\begin{array}{c}8 \\
11.9 \\
27.6\end{array}$ & $\begin{array}{c}35 \\
52.2 \\
63.6\end{array}$ & $\begin{array}{c}10 \\
14.9 \\
76.9\end{array}$ & $\begin{array}{c}67 \\
100.0 \\
57.3\end{array}$ \\
\hline $\begin{array}{l}\text { Yes } \\
\text { Row \% } \\
\text { Col \% } \\
\end{array}$ & $\begin{array}{c}6 \\
14.0 \\
30.0\end{array}$ & $\begin{array}{c}18 \\
41.9 \\
62.1\end{array}$ & $\begin{array}{c}18 \\
41.9 \\
32.7\end{array}$ & $\begin{array}{c}1 \\
2.3 \\
7.7\end{array}$ & $\begin{array}{c}43 \\
100.0 \\
36.8\end{array}$ \\
\hline $\begin{array}{l}\text { TOTAL } \\
\text { Row \% } \\
\text { Col } \%\end{array}$ & $\begin{array}{c}20 \\
17.1 \\
100.0\end{array}$ & $\begin{array}{c}29 \\
24.8 \\
100.0\end{array}$ & $\begin{array}{c}55 \\
47.0 \\
100.0\end{array}$ & $\begin{array}{c}13 \\
11.1 \\
100.0\end{array}$ & $\begin{array}{c}117 \\
100.0 \\
100.0\end{array}$ \\
\hline
\end{tabular}

Interpretation: Majority of Males whose decision depended upon the recovery time taken after vasectomy also believed that vasectomy causes long lasting pain. Association between belief of pain and Attitude towards Vasectomy ( $\mathrm{p}$ value $=0.004$ ).

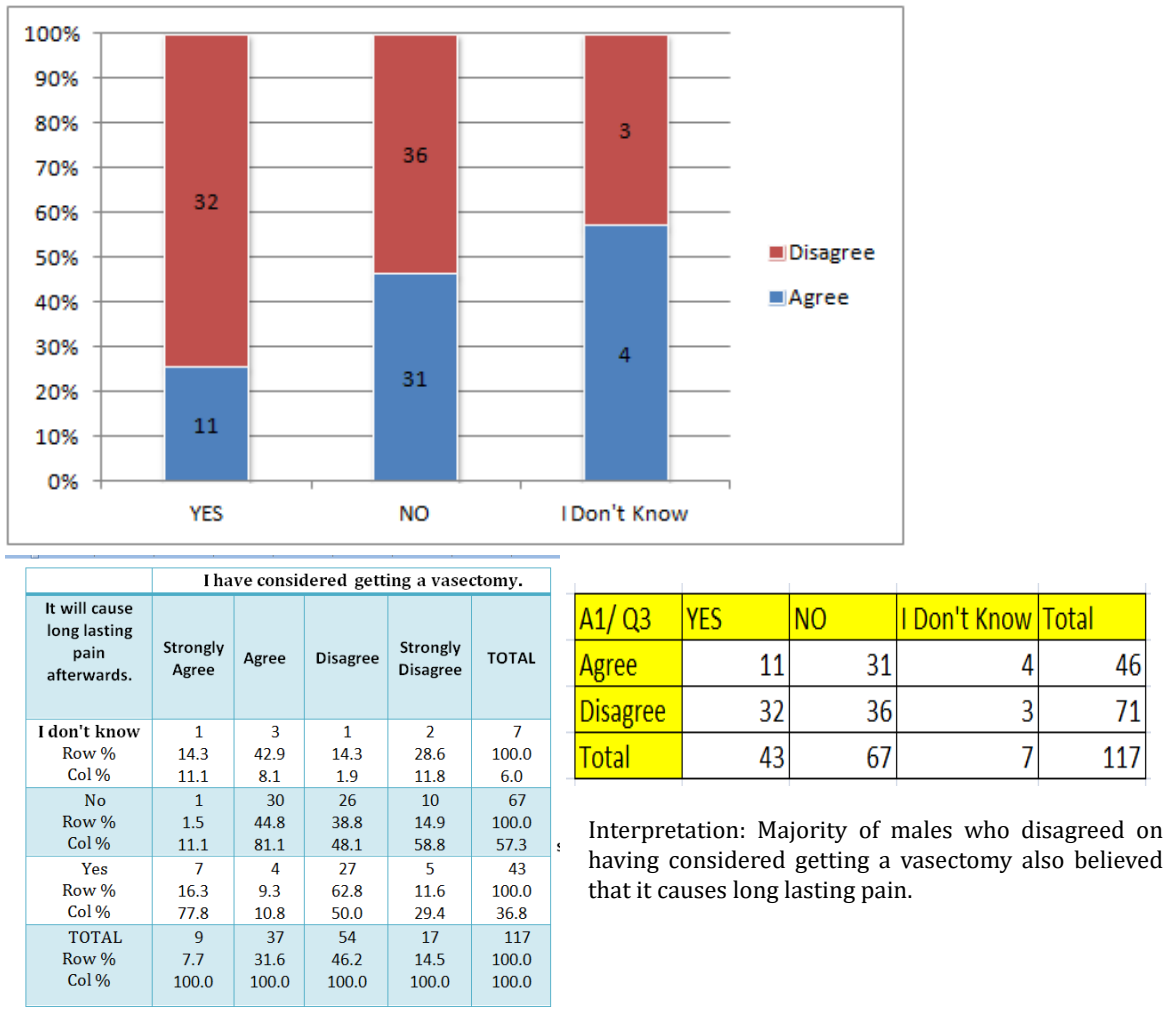

Figure 8. Responses towards attitude questions. 
Table 1. Observations. Variance: 4.5903 ; Standard deviation: 2.1425

\begin{tabular}{|c|c|c|c|}
\hline Score & Frequency & Percent & Cum. Percent \\
\hline $\mathbf{0}$ & 1 & $0.9 \%$ & $0.9 \%$ \\
\hline $\mathbf{1}$ & 7 & $6.0 \%$ & $6.8 \%$ \\
\hline $\mathbf{2}$ & 7 & $6.0 \%$ & $12.8 \%$ \\
\hline $\mathbf{3}$ & 5 & $4.3 \%$ & $17.1 \%$ \\
\hline $\mathbf{4}$ & 23 & $19.7 \%$ & $36.8 \%$ \\
\hline $\mathbf{5}$ & 20 & $17.1 \%$ & $53.8 \%$ \\
\hline $\mathbf{6}$ & 21 & $17.9 \%$ & $71.8 \%$ \\
\hline $\mathbf{7}$ & 20 & $17.1 \%$ & $88.9 \%$ \\
\hline $\mathbf{8}$ & 6 & $5.1 \%$ & $94.0 \%$ \\
\hline $\mathbf{9}$ & 4 & $3.4 \%$ & $97.4 \%$ \\
\hline $\mathbf{1 0}$ & 3 & $2.6 \%$ & $100.0 \%$ \\
\hline Total & 117 & $100.0 \%$ & $100.0 \%$ \\
\hline & & & \\
\hline
\end{tabular}

them had no idea about the nearest centers performing vasectomy, the government schemes or about insurance available for vasectomy. Assessing their attitude, it was found that (Figures 1-8 and Table 1):

- $61 \%$ men disagreed on having considered getting a vasectomy.

- $54 \%$ men also had a wrong notion that it makes a man more promiscuous.

- $54 \%$ of the men believed that the male should be the sole decision maker on the methods of family planning to be used.

- $46 \%$ of the men also feared their acceptance in society as vasectomy is considered as a taboo among the Indians.

- $43 \%$ surprisingly also believed that permanent contraception should only be for females.

- $42 \%$ of men also believed that the time taken for recovery would be a hindrance to their work.

- $39 \%$ believed that it was against their religion

- On analyzing the data, following associations were established.

- Most of the men who believed that the decision of methods of family planning solely rests on them, also believed that the permanent sterilization should be for women.

- According to education, it was found that poorly educated people had more incorrect notions about vasectomy.

- A strong association between the men who believed that it increases the chances of STDs having an extramarital affair also believed that vasectomy makes the men more promiscuous.

- Men whose decision depended upon the recovery time taken after the procedure also believed that it caused long lasting pain.

- Men who did not even consider having considered vasectomy done also believed it caused long lasting pain.

\section{Summary}

A study was conducted regarding the vasectomy awareness in 117 males in the age group 20 to 45 years (mean=33.95 years) having at least one child from different areas of Ahmedabad.
Assessing their knowledge, it was found that men are poorly aware about vasectomy (mean score $=5.42 / 11,47.27 \%$ ). It was found that they were unaware regarding insurance plans available for vasectomy $(67 \%)$ as well as the nearest centers that perform vasectomy operation (65\%). Majority of the males were also unaware about the government schemes (55\%). Many, [falsely] believe that the operation is irreversible (54.7\%) [3-7].

The assessment also shows that men falsely believe that vasectomy will make men more promiscuous (54\%), it can make men lose their sexual abilities (47\%), will increase their chances of STDs (41.9\%), can create long lasting pain (36.8\%), and that it is a similar process to castration (31\%). $47 \%$ males feared their acceptance in society. A strong association was found between the myths of vasectomy operation and the education of the assessed males.

Out of the total number of men assessed, $61 \%$ disagreed on having considered getting a vasectomy.

\section{Conclusion}

The men assessed during the project did not have the essential knowledge regarding the procedure of vasectomy. Many also did not possess the appropriate attitude towards undergoing it and many were unwilling to undergo the procedure due to various myths.

\section{Recommendation}

The problem of lack of awareness about vasectomy and the government schemes regarding the same can be eliminated. There should be more awareness regarding the "no scalpel" surgery in their content of public awareness to eliminate the myth regarding long lasting pain after surgery.

The family planning counsellor should inform the couple regarding the benefits of vasectomy over tubectomy during the cafeteria approach. To build the right kind of attitude, to create awareness "Social Marketing" for vasectomy still needs to be addressed with more intense and specific IEC in the protocol.

\section{References}

1. Trussell J, Guthrie KA (2011) Choosing a contraceptive: Efficacy, safety, and persona considerations. Contraceptive Technology. (20 $0^{\text {th }}$ edn), Atlanta: Ardent Media: 45-74.

2. Compensation for Tubectomy and Vasectomy Victims '(2014) Available from: http:// pib.nic.in/newsite/PrintRelease.aspx?relid=106949

3. Park K (1997) Park's Textbook of Preventive and Social Medicine. (23rd edn) Jabalpur: Banarsidas Bhanot.

4. WHO (2016) Scalpel versus No-scalpel Incision for Vasectomy. World Health Organization. N.p., n.d. Web.

5. https://vasectomy-information.com/

6. Arthur Allen. Vasectomy Risks and Benefits. Available from: https://www.webmd. $\mathrm{com} / \mathrm{men} /$ features/vasectomy-risks-benefits.

7. Ager JW, Werley HH, Allen DV, Shea FP, Lewis HY (1974) Vasectomy: Who Gets One and Why? Am J Public Health 64: 680-686. [Crossref]

Copyright: (C2018 Patel K. This is an open-access article distributed under the terms of the Creative Commons Attribution License, which permits unrestricted use, distribution, and reproduction in any medium, provided the original author and source are credited. 